\title{
Stabilization Period for Central Corneal Thickness, Anterior Chamber Depth, and Iridocorneal Angle Parameters After Deep Anterior Lamellar Keratoplasty in Keratoconus Patients
}

\author{
(D) Gonul Karatas Durusoy, ${ }^{1}$ (1) Mehmet Ozveren² \\ 1Department of Ophthalmology, Gaziantep Dr Ersin Aslan Training and Research Hospital, Gaziantep, Turkey \\ ${ }^{2}$ Department of Ophthalmology, Edirne Sultan 1. Murat State Hospital, Edirne, Turkey
}

\begin{abstract}
Objectives: The purpose of this study was to assess the stabilization of anatomical outcomes of central corneal thickness (CCT), anterior chamber depth (ACD), and iridocorneal angle (ICA) in keratoconus-affected eyes after deep anterior lamellar keratoplasty (DALK).

Methods: Keratoconus patients who underwent DALK surgery at Beyoğlu Eye Training and Research Hospital between January 2013 and May 2015 were retrospectively analyzed. Patients with data recorded preoperatively, I month postoperatively, and I, 6, and 12 months post suture removal, including refractive status, best corrected visual acuity (BCVA), CCT, $A C D$, and ICA parameters were included in the study. The CCT, ACD, and ICA parameters were assessed with anterior segment optical coherence tomography.

Results: A total of 42 eyes of 37 patients with a mean age of $30.5 \pm 10.5$ years were analyzed. The mean preoperative and post-suture removal I2th-month BCVA was I.4I \pm 0.43 logarithm of minimal angle of resolution (logMAR), and $0.34 \pm 0.1$ logMAR, respectively $(p<0.00 I)$. The ACD $(I 1 \% ; p<0.00 I)$ and ICA $(3 \% ; p=0.009)$ values significantly increased, whereas the CCT $(2 \% ; p=0.008)$ decreased after suture removal. The ICA and CCT values demonstrated stability I month after suture removal, and the ACD was stable 6 months after suture removal.

Conclusion: Our study results indicated that the ICA and CCT stabilized I month post suture removal and the ACD stabilized 6 months after suture removal. A waiting period of at least 6 months after suture removal is recommended before any post-DALK refractive surgery.

Keywords: Anterior chamber depth, deep anterior lamellar keratoplasty, iridocorneal angle, keratoconus
\end{abstract}

\section{Introduction}

Keratoconus is the most common form of bilateral corneal ectasia. Thinning of the corneal stroma leads to the cornea gradually taking on a conical shape, which can cause irregular astigmatism, myopia, and protrusion, and mild to marked vision impairment (I). Management of keratoconus varies depending on the progression of the disease $(I, 2)$.

Corneal collagen cross-linking is a well-established firstline therapy to prevent keratoconus progression and potentially also provide some improvement in visual acuity (VA) (3). Early cases of keratoconus can be managed with eyeglasses,

How to cite this article: Karatas Durusoy G, Ozveren M. Stabilization Period for Central Corneal Thickness, Anterior Chamber Depth, and Iridocorneal Angle Parameters After Deep Anterior Lamellar Keratoplasty in Keratoconus Patients. Beyoglu Eye J 202I; 6(I): I4-I8.

Address for correspondence: Gonul Karatas Durusoy, MD. Gaziantep Dr. Ersin Aslan Egitim ve Arastirma Hastanesi, Goz Hastaliklari Klinigi, Gaziantep, Turkey

Phone: +90 5077417341 E-mail: gnlkaratas@gmail.com

Submitted Date: November 01, 2020 Accepted Date: January 19, 2021 Available Online Date: February 17, 2021

${ }^{\circ}$ Copyright 2021 by Beyoglu Eye Training and Research Hospital - Available online at www.beyoglueye.com OPEN ACCESS This work is licensed under a Creative Commons Attribution-NonCommercial 4.0 International License. 
and contact lenses or intracorneal ring implants can be used for mild to moderate cases. Corneal transplantation is the final option for visual rehabilitation in patients who cannot tolerate or do not adequately benefit from more conservative alternatives $(\mathrm{I}, 3)$. Deep anterior lamellar keratoplasty (DALK) is a lamellar corneal graft technique. The donor cornea is transplanted leaving the endothelium and the Descemet's membrane (DM) intact, which reduces the incidence of peroperative and postoperative complications and graft rejection (4). DALK is now preferred to penetrating keratoplasty (PK) in patients with a healthy endothelium $(4,5)$.

DALK surgery is a partial-thickness procedure and the wound is stronger than that created with PK. Nonetheless, sometimes new problems may arise, such as ocular surface disease, glaucoma, suture-related problems, refraction change, or rejection. High refractive errors are frequently seen after keratoplasty, and may change in the postoperative period (6). Changes in refractive errors over time after DALK largely occur for 2 reasons. The primary cause of refractive instability is the avascular vertical wound between the donor and the recipient, which is extremely slow to heal and is never as strong as the virgin tissue. This can lead to variations in the wound architecture during the healing process $(7,8)$. Second, progressive changes in the graft tissue, and even recurrence of keratoconus, have been reported after $\operatorname{DALK}(9,10)$.

The purpose of this study was to assess the stabilization of the anatomical outcomes of CCT, ACD, and ICA of keratoconus-affected eyes following DALK surgery. To the best of our knowledge, this article is the first to report $A C D$ changes after DALK suture removal.

\section{Methods}

This study was conducted in accordance with the Declaration of Helsinki and with the approval of the ethics committee of Gaziantep University. All of the participants provided written, informed consent. The files of keratoconus patients who underwent DALK surgery at Beyoğlu Eye Training and Research Hospital between January 2013 and May 2015 were retrospectively examined. Additional ocular disease affecting $\mathrm{VA}$, the presence of any corneal scar extending to the DM, a history of acute hydrops, concurrent or pre-DALK ocular surgery, missing data for target parameters, or unremoved sutures were exclusion criteria.

A routine ophthalmological examination, including refraction testing, intraocular pressure (IOP) measurement, and anterior segment and fundus examinations, was performed for all of the eyes included in the study. Keratometry and corneal tomography examinations were also performed, and the diagnosis of keratoconus was confirmed based on clinical refraction, slit lamp, keratometry, and corneal tomography results. DALK surgery was performed for patients with advanced keratoconus and a viable endothelium.
All of the surgeries were performed under general anesthesia by a single surgeon using the big-bubble technique described by Anwar. Big bubble development was observed in all of the study patients. The diameter of the trepan was determined by measuring the cone width with a caliper (average: $7.50 \mathrm{~mm}$ ). The donor tissue was prepared using punch blades to be 0.25 larger than the recipient bed diameter. The endothelium was removed from the donor cornea using $0.06 \%$ trypan blue. The endothelium-free donor cornea was then sutured with 10/0 nylon on the recipient cornea. Single row continuous corneal suturing was used in all cases.

After the surgery, topical moxifloxacin $0.5 \%$, artificial tears (polyvinyl alcohol and povidone), and dexamethasone $0.1 \%$ were administered 6 times a day. The use of eye drops was gradually tapered over 6 months. The sutures were removed between 6 months and 12 months after the surgery.

The CCT, ICA, and ACD parameters measured at the final preoperative visit, I month postoperatively, and I, 6, and 12 months post suture removal, as well as the best corrected visual acuity (BCVA) and manifest spherical equivalent values at the final preoperative and postoperative visits, were recorded. The manifest astigmatism and spherical equivalent values were determined using subjective refraction procedures. The ICA, ACD, and CCT results were obtained using anterior segment optical coherence tomography (AS-OCT) (Visante; Carl Zeiss AG, Oberkochen, Germany). These tests were performed by I experienced technician to reduce variability.

\section{Statistical Analysis}

The mean and SD values of the study data were used as descriptive statistics. The normality of the distribution of the variables was examined using the Kolmogorov-Smirnov test. A dependent sample t-test and the Wilcoxon test were used in the analysis of quantitative data. IBM SPSS Statistics for Windows, Version 21.0 software (IBM Corp., Armonk, NY, USA) was used to perform the analyses. A p value of $<0.05$ was considered significant.

\section{Results}

In total, 42 eyes of 37 patients were included in the study. Twenty (54.06\%) of the patients were female and 17 (45.94\%) were male. The mean age of the patients was $30.5 \pm 10.5$ years (range: 14-56 years).

The preoperative and postoperative visual and refractive changes are shown in Table I. T-tests of dependent groups indicated that the mean postoperative BCVA was statistically significantly higher than the preoperative value $(p<0.00 \mathrm{I})$.

The CCT, ICA, and ACD values measured at the target points are displayed in Table 2. A significant decrease in mean ACD (I4\%; $\mathrm{p}<0.00 \mathrm{I})$ and ICA $(4 \% ; \mathrm{p}=0.004)$ values was seen from the last preoperative visit to the first-month postoperative visit. There was a significant increase from the 
Table I. Visual and refractive results before and after surgery

\begin{tabular}{lc} 
BCVA & Mean \pm SD \\
\hline Final preoperative visit & $\mathrm{I} .4 \mathrm{I} \pm 0.43 \log M A R *$ \\
Final postoperative visit & $0.34 \pm 0.17 \log M A R *$ \\
Final postoperative visit astigmatism & $3.8 \pm 2.3 \mathrm{D}$ \\
Final postoperative visit spherical equivalent & $-2.7 \pm 3.2 \mathrm{D}$
\end{tabular}

${ }^{*}$ < 0 0.00I (paired samples t-test); BCVA: Best corrected visual acuity; D: Diopter; logMAR: Logarithm of the minimum angle of resolution.

I-month postoperative visit to the I-month post-suture removal visit in ACD (II\%; $<<0.00 I)$ and ICA (3\%; $p=0.009)$ values. The mean $A C D$ value increased significantly between the first-month and the sixth-month post-suture removal measurements ( $4 \% ; p=0.004)$, whereas no significant change was observed in the ICA in the same period ( $p>0.05)$. There was no significant change in the ACD or ICA between the sixth month and I year post suture removal $(p>0.05)$.

The CCT measurement increased from the last preoperative visit to the first-month postoperative visit (46\%; $\mathrm{p}<0.00 \mathrm{I})$ and decreased from the first-month postoperative visit to the post-suture removal first-month visit $(2 \%$, $p=0.008)$. No significant difference was detected after the first-month post-suture removal visit $(p>0.05)$.

\section{Discussion}

The purpose of this study was to determine the stability of CCT, ACD, and ICA parameters in eyes with keratoconus after DALK.

The incidence of glaucoma has been reported to be between $10 \%$ and $53 \%$ after PK and $0 \%$ and $17 \%$ after DALK. A high IOP may be caused by long-term steroid use, changes in ICA architecture, changes in trabecular architecture caused by intraoperative and postoperative mechanical forces, or inflammation (I3). ICA measurements may reflect mechanical angular distortion. In a study evaluating ICA change at 6 months after PK, a slight, non-significant decrease was re- ported (14). Our results indicated that the mean ICA value was slightly, but significantly, lower at I month after DALK. The ICA was found to be slightly, but significantly, higher after suture removal. These differences were probably a result of tension changes due to the sutures. The mean ICA was found to be stable at the first month after suture removal. We observed statistically significant ICA changes, but they were small and the clinical significance should be further evaluated.

Significant increases in BCVA in keratoconus patients for 3 to 6 months after DALK surgery have been reported, however, this is primarily a result of the reduction in irregular astigmatism $(9,12)$. In this study, consistent with the literature, we found a significant improvement in BCVA at the final visit compared with measurements taken before surgery.

The ACD in keratoconus patients is expected to be high due to ectasia. Ort et al. (14) analyzed PK results in keratoconus patients and reported that the $A C D$ values in the preoperative and postoperative sixth-month visits were $3.92 \pm 0.47 \mathrm{~mm}$ and $3.01 \pm 0.55 \mathrm{~mm}$, respectively $(23 \%$ decrease). However, the evaluation was made before removal of the sutures. In another study of PK in keratoconus patients, the $A C D$ values at preoperative and postoperative 2-year visits were $3.72+0.43 \mathrm{~mm}$ and $3.47+0.33 \mathrm{~mm}$, respectively ( $7 \%$ decrease). In the same study, it was reported that the sutures were removed at the postoperative 12th month, but the effect of suture removal on ACD could not be evaluated because no post-PK value was given (I5). In our study, the ACD value determined with AS-OCT decreased from $3.78 \pm 0.52 \mathrm{~mm}$ to $3.27 \pm 0.49 \mathrm{~mm}$ ( $14 \%$ decrease) in the first month after DALK, which is consistent with the literature. After the suture removal, it increased to $3.62 \pm 0.54 \mathrm{~mm}(1 \mathrm{I} \%$ increase) in the first month and $3.77 \pm 0.48 \mathrm{~mm}$ ( $4 \%$ increase) in the sixth month, and stabilized afterwards. It is not surprising that the ACD increased with suture removal, but the continuation of this change shows that the adaptation of the cornea takes more than I month.

Corneal thinning is a feature of keratoconus, and an in-

Table 2. CCT, ICA, and ACD values measured using AS-OCT

\begin{tabular}{|c|c|c|c|c|c|c|c|c|c|}
\hline AS-OCT & $\begin{array}{c}\text { Final } \\
\text { preoperative } \\
\text { visit }\end{array}$ & $\mathbf{P}_{\text {diff }}$ & $\begin{array}{c}\text { Postoperative } \\
\left.\right|^{\text {st }} \text { month }\end{array}$ & $\mathbf{P}_{\text {diff }}$ & $\begin{array}{c}\text { Post-suture } \\
\text { removal I st } \\
\text { month }\end{array}$ & $\mathbf{P}_{\text {diff }}$ & $\begin{array}{c}\text { Post-suture } \\
\text { removal } \\
\text { 6 }^{\text {th }} \text { month }\end{array}$ & $\mathbf{P}_{\text {diff }}$ & $\begin{array}{c}\text { Post-suture } \\
\text { removal } \\
12^{\text {th }} \text { month }\end{array}$ \\
\hline $\mathrm{ACD}(\mathrm{mm})$ & $3.78 \pm 0.52$ & $<0.001 \mathrm{t}$ & $3.27 \pm 0.49$ & $<0.001 \mathrm{t}$ & $3.62 \pm 0.54$ & $0.008 w$ & $3.77 \pm 0.48$ & $0.214 \mathrm{w}$ & $3.8 I \pm 0.58$ \\
\hline ССТ $(\mu \mathrm{m})$ & $354 \pm 80$ & $<0.001 \mathrm{t}$ & $517 \pm 66$ & $0.008 w$ & $506 \pm 57$ & $0.141 \mathrm{w}$ & $503 \pm 58$ & $1.000 \mathrm{w}$ & $503 \pm 55$ \\
\hline ICA (\%) & $44.9 \pm 10$ & $0.004 \mathrm{w}$ & $43.1 \pm 8.8$ & $0.009 w$ & $44.3 \pm 8.2$ & $0.760 \mathrm{w}$ & $44.7 \pm 7.9$ & $0.571 \mathrm{w}$ & $43.7 \pm 8.0$ \\
\hline
\end{tabular}

Pdiff: Probability of intragroup change by chance; t: paired t-test; w:Wilcoxon test;ACD:Anterior chamber depth;AS-OCT:Anterior segment optical coherence tomography; CCT: Central corneal thickness; ICA: Iridocorneal angle. 
crease in CCT after corneal transplantation surgery is expected. An increased CCT reported in long-term follow-up of PK patients has been attributed to progressive endothelial loss (16). In our study, the CCT values were $334 \pm 50$ $\mu \mathrm{m}, 532 \pm 62 \mu \mathrm{m}$, and $5 \mathrm{I} 7 \pm 58 \mu \mathrm{m}$ at the preoperative visit, I month post-DALK, and I month post-suture removal visit, respectively, and stabilized afterwards. A CCT increase after surgery is consistent with results in the literature. There was also a slight difference between the first month after surgery and the first month after suture removal. These data seem to indicate that functional attachment of the endothelium and lamellar graft requires more than I month.

Although spherical equivalent, mean keratometry, and astigmatism values decrease after DALK surgery in keratoconus patients, it is not uncommon to encounter a high refractive error after surgery. It has been reported that myopic shift formation continued for I to 6 months after suture removal, but the spherical equivalent value remained stable at 6 to 24 months. Refractive astigmatism and mean keratometry values have been reported to be stable at I to 24 months after suture removal $(9,12)$.

Non-surgical, conservative methods, such as eyeglasses and contact lenses, are the initial means used to rehabilitate post-DALK refractive errors. When these modalities are not adequate, corneal and intraocular surgical correction options are the treatment of choice $(I I, I 7)$.

Several corneal surgery options are available, such as laser-assisted surgery and manual keratotomy $(I|| 8-2 \mid$,$) .$ The prerequisites for all surgeries are a minimum interval of 6 months and a stabilized refractive state after suture removal. Improved uncorrected VA and decreased refractive error are standard $(I I, \mid 8,20)$. In a study reporting the results of treatment with LASIK for refractive error after DALK suture removal, it was reported that the mean keratometry, spherical equivalent, and uncorrected VA did not change between I month after LASIK and the final visit (mean: I I months). The authors also reported that $67 \%$ of the patients had a subjective refractive error within \pm 1.0 diopters (D) and that $92 \%$ had within $\pm 2.0 \mathrm{D}$ (II). In our study, we observed that the CCT, which may be important for corneal refractive surgery, did not change beyond I month after suture removal.

Intraocular surgical options include the implantation of a variety of lenses. The prerequisites for surgery are similar to those for corneal refractive surgery. Improved uncorrected VA and decreased refractive error have regularly been reported (22-24). Newer generation IOL calculation formulas, such as the Haigis and Holladay formulas, require $A C D$ measurement. Formulas including the $A C D$ parameter are recommended for eyes with abnormal anterior segment anatomy (25). Patients who have undergone corneal transplantation may be included in this group, but since the $A C D$ may change in the postoperative period, determination of the optimal timing for intraocular surgery is important for a satisfactory outcome. In addition, in a study in which iris claw lenses were implanted after DALK, there was a prerequisite that the ACD should be greater than $3.2 \mathrm{~mm}$ (23). In our study, we found that the ACD had stabilized 6 months after suture removal. To the best of our knowledge, this article is the first to report this finding, which may be important for the success of intraocular refractive surgery.

Limitations of our study include a small patient group; follow-up points limited to the final preoperative visit, I month post DALK, and I, 6, and 12 months after suture removal; and the fact that keratometry, manifest refraction, and IOP measurements were not included.

\section{Conclusion}

Although a significant change in the corneal and anterior chamber parameters occurs after DALK surgery, stability was attained after suture removal. According to our study results, the CCT and ICA parameters were stable between the $1^{\text {st }}$ and $12^{\text {th }}$ months, and the ACD was stable between 6 and 12 months after suture removal.

\section{Disclosures}

Ethics Committee Approval: Gaziantep University Clinical Research Ethics Committe, 2018/300, 05.12.2018.

Peer-review: Externally peer-reviewed.

Conflict of Interest: None declared.

Authorship Contributions: Involved in design and conduct of the study (GKD); preparation and review of the study (GKD, MO); data collection (GKD); and statistical analysis (MO).

\section{References}

I. Romero-Jiménez M, Santodomingo-Rubido J, Wolffsohn JS. Keratoconus: a review. Cont Lens Anterior Eye 2010;33:15766; quiz 205. [CrossRef]

2. Rabinowitz YS. Keratoconus. Surv Ophthalmol 1998;42:297319. [CrossRef]

3. Maier P, Reinhard T, Kohlhaas M. Corneal collagen crosslink- ing in the stabilization of keratoconus. Dtsch Arztebl Int 2019;1 16:184-90. [CrossRef]

4. Parker JS, van Dijk K, Melles GR. Treatment options for advanced keratoconus: A review. Surv Ophthalmol 2015;60:45980. [CrossRef]

5. Al-Kharashi SA, Al-Obailan MM, Almohaimeed M, Al-Torbak AA. Deep anterior lamellar Keratoplasty. Saudi J Ophthalmol 2009;23:203-9. [CrossRef]

6. Noble BA, Agrawal A, Collins C, Saldana M, Brogden PR, Zuberbuhler B. Deep anterior lamellar keratoplasty (DALK): visual outcome and complications for a heterogeneous group of corneal pathologies. Cornea 2007;26:59-64. [CrossRef] 
7. Feizi S, Javadi MA, Rezaei Kanavi M. Recurrent keratoconus in a corneal graft after deep anterior lamellar keratoplasty. J Ophthalmic Vis Res 2012;7:328-3I.

8. Terry MA. The evolution of lamellar grafting techniques over twenty-five years. Cornea 2000;19:6 I I-6. [CrossRef]

9. Feizi S, Javadi MA, Behnaz N, Fani-Hanife S, Jafarinasab MR. Effect of suture removal on refraction and graft curvature after deep anterior lamellar keratoplasty in patients with keratoconus. Cornea 2018;37:39-44. [CrossRef]

10. Javadi MA, Feizi S, Kanavi MR, Faramarzi A, Hashemian J, Mirbabaee F. Acute hydrops after deep anterior lamellar keratoplasty in a patient with keratoconus. Cornea 201 I;30:59I-4. [CrossRef]

I I. Baltaziak M, Chew HF, Podbielski DW, Ahmed IIK. Glaucoma after corneal replacement. Surv Ophthalmol 2018;63:135-48.

12. Ort A, Gunes A, Kandemir B, Calısır K, Kalaycı M, Genc O, et al. Evaluation of the cornea and anterior chamber morphologic changes after penetrating keratoplasty in patients with keratoconus. Eye Contact Lens 2017;43:236-9. [CrossRef]

13. Javadi MA, Feizi S, Rahmani S, Khajuee-Kermani P. Refractive stability after deep anterior lamellar keratoplasty for keratoconus. Cornea 2018;37:1506-10. [CrossRef]

14. Italon C, Pieh S, Hanselmayer G, Kahraman G, Kaminski S, Skorpik $C$, et al. Changes of axial length and keratometry after keratoplasty for keratoconus using the guided trephine system. Am J Ophthalmol 2002; 134:696-700. [CrossRef]

I5. Touzeau O, Borderie VM, Allouch C, Laroche L. Late changes in refraction, pachymetry, visual acuity, and corneal topography after penetrating keratoplasty. Cornea 2006;25: I46-52. [CrossRef]

16. Acar BT, Utine CA, Acar S, Ciftci F. Laser in situ keratomileusis to manage refractive errors after deep anterior lamellar keratoplasty. J Cataract Refract Surg 2012;38:1020-7. [CrossRef]

17. Poole TR, Ficker LA. Astigmatic keratotomy for post-kerato- plasty astigmatism. J Cataract Refract Surg 2006;32: I I 75-9.

18. Nubile M, Carpineto P, Lanzini M, Calienno R, Agnifili L, Ciancaglini $M$, et al. Femtosecond laser arcuate keratotomy for the correction of high astigmatism after keratoplasty. Ophthalmology 2009; I 16: 1083-92. [CrossRef]

19. Szentmáry N, Seitz B, Langenbucher A, Naumann GO. Repeat keratoplasty for correction of high or irregular postkeratoplasty astigmatism in clear corneal grafts. Am J Ophthalmol 2005;139:826-30. [CrossRef]

20. Sorkin N, Einan-Lifshitz A, Abelson S, Boutin T, Showail M, Borovik $A$, et al. Stepwise guided photorefractive keratectomy in treatment of irregular astigmatism after penetrating keratoplasty and deep anterior lamellar keratoplasty. Cornea 2017;36:1308-15. [CrossRef]

21. Arriola-Villalobos P, Díaz-Valle D, Güell JL, Iradier-Urrutia MT, Jiménez-Alfaro I, Cuiña-Sardiña R, et al. Intrastromal corneal ring segment implantation for high astigmatism after penetrating keratoplasty. J Cataract Refract Surg 2009;35: 1878-84. [CrossRef]

22. Srinivasan S, Ting DS, Lyall DA. Implantation of a customized toric intraocular lens for correction of post-keratoplasty astigmatism. Eye (Lond) 20I 3;27:53 I-7. [CrossRef]

23. Malheiro L, Coelho J, Neves MM, Gomes M, Oliveira L. Phakic lens implantation after deep anterior lamellar keratoplasty: retrospective case series analysis with long-term follow-up. Clin Ophthalmol 2019;13:2043-52. [CrossRef]

24. Meyer JJ, McGhee CN. Supplementary, sulcus-fixated intraocular lens in the treatment of spherical and astigmatic refractive errors in pseudophakic eyes after keratoplasty. Cornea 2015;34:1052-6. [CrossRef]

25. Xia T, Martinez CE, T sai LM. Update on intraocular lens formulas and calculations. Asia Pac J Ophthalmol (Phila) 2020;9:18693. [CrossRef] 